\title{
Molecular and Cellular Mechanisms by Which Diabetes Mellitus Promotes the Development of Atherosclerosis
}

\author{
GEOFF H. WERSTUCK
}

\begin{abstract}
Recent decades have witnessed a significant increase in the incidence of diabetes mellitus primarily driven by population trends toward weight gain and sedentary lifestyles. Diabetes mellitus is a leading cause of blindness, renal failure, lower limb amputation, and an independent risk factor for atherosclerotic cardiovascular disease (CVD) and stroke. In fact, individuals with diabetes have a two- to fourfold increased risk of myocardial infarction (MI) and stroke that accounts for over $65 \%$ of diabetic mortality. Despite a vast amount of research, the molecular and cellular mechanisms that predispose individuals with diabetes to the development and progression of atherosclerosis are not understood. This chapter summarizes the current state of our knowledge of these conditions as well as some of the animal models that are being used to further increase our understanding. In addition, pathways and mechanisms that may link diabetes, and hyperglycemia in particular, to the development and progression of atherosclerosis are discussed. The continued investigation of identified pathways, linking hyperglycemia and diabetes mellitus to atherosclerosis, and the discovery of novel mechanisms and targets will be important to the development of new and effective antiatherosclerotic therapies tailored to individuals with diabetes.
\end{abstract}

Keywords: accelerated atherosclerosis; animal models; diabetes mellitus; hyperglycemia; molecular mechanisms

\section{Introduction}

The last few decades have witnessed a dramatic, worldwide increase in the incidence of diabetes mellitus. Driven by changes in lifestyle and an escalating rate of obesity, the number of individuals with diabetes is expected to reach 300 million by the year $2025[1,2]$. Therefore, the diabetes epidemic is, and will continue to be, a global health crisis. Complications associated with diabetes make it a leading cause of blindness, renal failure, and lower limb amputations as well as an important, independent risk factor for atherosclerotic cardiovascular disease (CVD). CVD accounts for over $65 \%$ of diabetic mortality. In fact, diabetes mellitus is "a coronary heart disease risk equivalent" meaning that individuals with diabetes have the same risk of myocardial 
infarction (MI) as nondiabetic persons who have had a previous MI [3-5]. Despite a tremendous amount of research, the treatment and prevention of diabetes-associated CVD is currently limited by our lack of understanding of the molecular and cellular mechanisms by which diabetes mellitus promotes atherosclerosis. This chapter will focus upon our current understanding of this problem, the model systems that are being used to further increase our knowledge and the potential future directions of this research.

\section{Diabetes Mellitus}

Diabetes mellitus is currently defined as a condition with casual blood glucose values are $\geq 11.1 \mathrm{mmol} / \mathrm{L}$, or fasting plasma glucose $\geq 7.0 \mathrm{mmol} / \mathrm{L}$, or glucose levels $\geq 11.1 \mathrm{mmol} / \mathrm{L} 2 \mathrm{~h}$ after an oral glucose tolerance test [6]. Pathologically, the term diabetes mellitus describes a heterogeneous group of metabolic disorders characterized by chronic hyperglycemia. These include conditions under which the body cannot produce insulin and/or cannot effectively respond to the insulin that is being produced. There are two major forms of diabetes; type 1 (T1D), formerly known as juvenile diabetes or insulin-dependent diabetes mellitus (IDDM) and type 2 (T2D), formerly known as adult onset or noninsulin-dependent diabetes mellitus (NIDDM). T1D and T2D are, in essence, two distinctly different diseases that present an overlapping array of signs and symptoms.

T1D is characterized by an absolute insulin deficiency that results from an autoimmune-mediated depletion of insulin secreting pancreatic $\beta$ cells $[7,8]$. Typically, T1D develops with a rapid onset in children, with a peak incidence at 14 years of age. T1D makes up approximately $10 \%$ of the total number of cases of diabetes mellitus. Recent breakthroughs in $\beta$ cell transplantation may lead to an eventual cure for T1D. Until that time, the only treatment is the tight self-monitoring of plasma glucose and the administration of exogenous insulin according to carbohydrate intake.

T2D accounts for the remaining $90 \%$ of cases of diabetes mellitus. T2D is characterized by a relative insulin deficiency that arises from a combination of peripheral tissue insulin resistance and impaired $\beta$ cell function $[9,10]$. Tissues expressing the insulin responsive GLUT4 glucose transporter, including adipose, and skeletal muscle and liver are particularly relevant to insulin resistance. The onset of T2D is relatively gradual and, until recently, with rare exceptions, affected only adults. However with the dramatic increase in childhood obesity, there has been an alarming increase in the diagnosis of T2D in children. Depending on severity, T2D can be controlled by using a combination of lifestyle modifications (diet and exercise), medications that increase insulin sensitivity and exogenous insulin.

Despite their distinctly different etiologies, both T1D and T2D are characterized by chronic hyperglycemia. Furthermore, there is a strong correlation between hyperglycemia and both micro- and macrovascular disease [11-15]. 
The negative effects of elevated glucose levels on vascular function can include decreased proliferation of endothelial cells, the impairment of some parameters of vascular responsiveness, and increased endothelial programmed cell death [16-18]. It is well established that aggressive blood glucose lowering significantly decreases the incidence and severity of microvascular disease including retinopathy, renal failure, and peripheral nerve dysfunction [11, 12]. Recent evidence suggests that increased glycemic control also correlates with a reduction in macrovascular disease, however the relationship between glucose lowering and a decrease in CVD has been much more difficult to demonstrate $[12,19,20]$. Several explanations have been put forth to rationalize the inability to clinical trials to demonstrate a strong improvement in cardiovascular outcomes through glycemic control including the possibilities that the trials were underpowered, too short in duration or were too focused upon fasting glucose rather than postprandial glucose levels. Alternatively, these findings may indicate that the quality of glycemic control presently achievable is insufficient to be effective in protecting against macrovascular disease. Therefore, even short-term deviations in the control of blood glucose may promote vascular dysfunction.

The pathophysiology of T2D-associated CVD is further complicated by multiple risk factors, collectively known as the metabolic syndrome, that commonly accompany chronic hyperglycemia. The metabolic syndrome is clinically defined as a combination of abdominal obesity, insulin resistance (prediabetes), atherogenic dyslipidemia, and hypertension [21]. The metabolic syndrome is a major cause of morbidity and mortality with CVD being the primary clinical outcome [21]. Other complications can include respiratory difficulties, chronic skeletal muscle problems, gallbladder disease, infertility, hepatic steatosis, circulatory problems, and certain cancers [22, 23].

Therefore, while a role for hyperglycemia in the development and progression of atherosclerosis is supported by a great deal of basic research, the clinical role of elevated glucose levels in macrovascular disease is less clear. Furthermore, despite a great deal of research the mechanisms that may link high glucose concentrations to the molecular and cellular pathways of disease development are not fully understood. This review will focus on potential direct proatherogenic consequences of hyperglycemia.

\section{Model Systems}

A major challenge facing researchers, who study the role of diabetes mellitus in macrovascular disease, is the inherent resistance of most rodent strains to atherosclerotic plaque development. In commonly used rodent strains, hyperglycemia and diabetes alone are not sufficient to promote the development of lesions [24]. Even in strains that can develop vascular lesions, diabetesaccelerated atherosclerosis appears, in many cases, to depend upon hyperlipidemia, either resulting from a high fat diet or a genetic deficiency, as with the 
ApoE-deficient or LDLR-deficient mouse [24, 25]. The general resistance of mice to atherogenesis may result, at least in part, from the observation that wild-type mice, in contrast with humans, have barely detectable lowdensity lipoprotein (LDL) and very low-density lipoprotein (VLDL) levels. The induction of hyperlipidemia, through dietary or genetic manipulation, "humanizes" the lipid profiles of mice by significantly elevating both VLDL and LDL [24-26].

Rodent models of diabetes mellitus and hyperglycemia can be generally categorized as; (i) models in which diabetes is chemically induced, (ii) strains that have been inbred and selected for the existence of chronic hyperglycemia, or (iii) genetically engineered mouse models of diabetes (reviewed in [27]). Each model will possess a number of advantages and disadvantages depending upon the particular study and the experimental design. In general, models of T1D are useful to study the effects of chronic hyperglycemia in isolation whereas T2D models may be more physiologically relevant, abet more complicated by additional CVD risk factors such as obesity, dyslipidemia, hypertension, and perhaps hyperinsulinemia [27].

Commonly used, inbred models of spontaneous, chronic hyperglycemia, including the nonobese diabetic (NOD) mouse, the KK mouse, the Goto Kakizaki rat, and the bio-breeding (BB) rat, which are very useful in the study of hyperglycemia and many aspects of diabetes mellitus, including microvascular complications, are resistant to the development of atherosclerosis.

Many researchers chemically induce hyperglycemia in existing models of atherosclerosis such as the LDLR or ApoE knockout mouse models that spontaneously develop atherosclerosis [28]. The most commonly used animal models involve the administration of compounds, such as alloxan or streptozotocin (STZ), which are selectively toxic to pancreatic $\beta$ cells. Alloxan (2,4,5,6-tetraoxypyrimidine;5,6-dioxyuracil) can be administered parentally, intravenously intraperitoneally, or subcutaneously [29]. It is rapidly taken up not only by pancreatic $\beta$ cells but also by hepatocytes. Beta cells are believed to be especially sensitive to the reactive oxygen species that are produced in the cyclical interconversion of alloxan to dialuric acid [30]. The effective range of diabetogenic dose is relatively narrow and great care must be taken to minimize the side effects of this compound [29]. STZ is usually administered as a single large dose that is directly toxic to $\beta$ cells or by multiple low doses (e.g., five consecutive doses of $40 \mathrm{mg} / \mathrm{kg}$ body weight) that appear to induce $\beta$ cell destruction by an immune-mediated process. STZ is a nitrosurea derivative that enters pancreatic $\beta$ cell through the GLUT 2 transporter [31]. In low-to-moderate doses, STZ is selectively toxic to pancreatic $\beta$ cells. STZ-induced diabetes accelerates atherosclerosis in ApoE-deficient mice and BALBc mice fed an atherogenic diet [24, 25]. An advantage of the alloxan and STZ-induced models of diabetes mellitus is that they permit the examination of the effects of hyperglycemia in the absence of other variables that are often associated with T2D including obesity and hyperinsulinemia. One complication of chemically induced 
hyperglycemia is that, over time, dyslipidemia develops thereby making it difficult to differentiate whether accelerated lesion development is a result of elevated plasma glucose or lipid levels [25, 32, 33]. In fact, in at least some models, the STZ-associated dyslipidemia appears to be essential for the acceleration of atherosclerosis and STZ-induced hyperglycemia alone fails to accelerate lesion development [33-35].

Transgenic models of T2D, such as the ob/ob mouse have been crossed with atherosclerosis-prone strains including the LDLR knockout mouse. Not surprisingly, these double knockout mice exhibit severe hypertriglyceridemia, hypercholesterolemia, and accelerated atherosclerosis beyond either model individually [36]. Recently a transgenic model of T1D has been developed in which $\beta$ cell death can be induced, at will, by viral infection in an LDLR-deficient (proatherogenic) genetic background [32]. The advantage of this model is that $\beta$ cell death can be specifically induced at any time and the uninfected mice act as a normoglycemic control. Hyperglycemia, in the absence of dyslipidemia, is sufficient to accelerate atherosclerosis in this model [32].

\section{Potential Mechanisms by Which Hyperglycemia Accelerates Atherosclerosis}

Atherosclerosis is a disease of the walls of major muscular arteries that involves inflammation and the accumulation of lipids (reviewed in [37, 38]). It is believed to originate as a response to insult or injury to the endothelial layer. The damaged endothelial cells increase the expression of adhesion proteins ( $\beta 2$ integrin, PCAM-1, VCAM, ICAM, P-, and E-selectins) and chemotactic factors (monocyte chemotactic protein, MCP-1) factors that actively recruit monocytes and $\mathrm{T}$ lymphocytes to the vessel wall. Increased endothelium permeability allows the infiltration of monocytes and $\mathrm{T}$ lymphocytes as well as of lipoprotein particles, especially LDL, into the intima. The activated monocytes differentiate into macrophages expressing scavenger receptors (SR-A, CD36) that recognize oxidized, and otherwise modified, LDL particles. Scavenging macrophages become engorged with LDL-derived cholesterol and take on the appearance of a foam cell. Early lesions consist almost solely of foam cells and are known as fatty streaks. As lesion development progresses, activated macrophages/foam cells and $\mathrm{T}$ lymphocytes further simulate the inflammatory process through the secretion of matrix metalloproteases (MMPs) and cytokines (IFN- $\gamma$ ) that stimulate vascular smooth muscle cell (VSMC) growth and migration into the intima. VSMCs produce and secrete extracellular matrix that becomes a fibrous cap that covers the lesion. Foam cell death leaves a growing mass of extracellular debris, known as the necrotic core that includes lipids and many procoagulant proteins (tissue factor). The action of MMPs on the components of the fibrous cap can result in cap thinning and plaque instability. The majority of MIs and strokes 
are thought to occur when plaques rupture and the blood comes into contact with the necrotic core, forming a thrombus or clot [37, 38].

In diabetic patients, the atherogenic process is thought to occur through an identical series of events. Atherosclerotic lesions isolated from diabetic patients are generally more advanced but otherwise indistinguishable from those isolated from nondiabetic patients $[39,40]$. Individuals with diabetes have a two- to fourfold-increased risk of coronary heart disease and a fourfoldincreased risk of mortality from heart disease [4]. The reasons for this are not clear. Diabetes/hyperglycemia may promote the development of CVD by increasing the incidence or extent of endothelial injury, by accelerating the development or growth of a plaque, and/or by decreasing plaque stability.

Several mechanisms by which hyperglycemia may promote atherosclerosis have been proposed. In general these involve the effects of elevated levels of intracellular glucose and the increased availability of glucose-derived molecules in cells of the vascular wall (Fig. 13.1).

\section{The Polyol Pathway}

The conversion of glucose to sorbitol occurs at a low rate under normoglycemic conditions due to the high $K_{\mathrm{m}}$ of aldose reductase for glucose. The flux through this pathway is significantly elevated under diabetic conditions as intracellular glucose concentrations rise [41]. High sorbitol concentration may be directly toxic to some cell types. In others, increased aldose reductase activity has been shown to lead the increased consumption of NADPH and

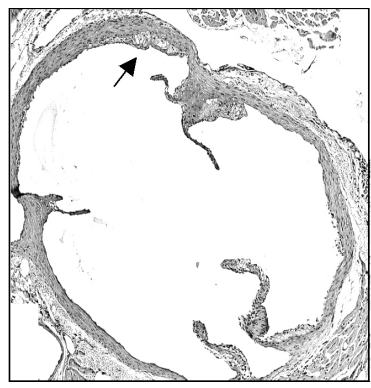

control

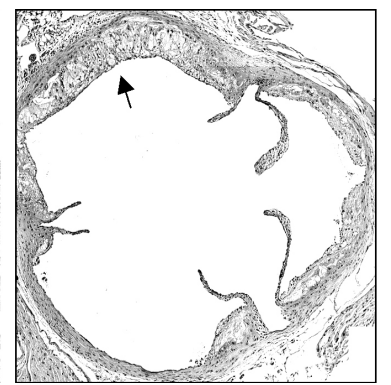

diabetic

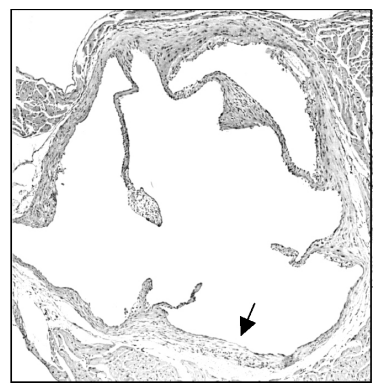

diabetic + insulin

FIGURE 13.1. Streptozotocin (STZ)-induced hyperglycemia promotes accelerated atherosclerosis in ApoE-deficient mice. ApoE-deficient mice were give ten intraperitoneal injections of STZ ( $40 \mathrm{mg} / \mathrm{kg}$ body weight) or an equal volume of saline solution (control) before 8 weeks of age. Plasma glucose levels increase to approximately 20 to 25 $\mathrm{m} M$ in diabetic mice versus 7 to $9 \mathrm{~m} M$ in controls. Atherosclerotic lesions at the aortic sinus (indicated by arrows), examined at 15 weeks of age, are significantly larger and more advanced in the hyperglycemic mice than in nondiabetic mice or diabetic mice with a subcutaneous, slow release insulin pellet (diabetic + insulin). 
depletion of GSH levels that can result in increased levels of reactive oxygen species (ROS) and subsequent cellular damage [42]. It has also been proposed that the conversion of sorbitol to 3-deoxyglucosone can feed into the production of advanced glycation endproducts (AGEs - see below).

Although the link between the polyol pathway and atherogenesis has been inferred, there is very little evidence to support a role in macrovascular disease. Studies focusing on the microvascular benefits of aldose reductase inhibition have, to date, produced mixed results [43-45]. Zenarestat, a potent aldose reductase inhibitor and potential treatment for diabetes-associated neuropathy, did reach phase III before the trial was suspended due to signs of renal toxicity in some patients $[45,46]$.

\section{The Hexosamine Pathway}

The shunting of excess intracellular glucose through the hexosamine pathway may also be relevant to the development of macrovascular complications of diabetes (Fig. 13.2). In a typical cell, under normoglycemic conditions, $1 \%$ to $3 \%$ of total glucose will be converted to glucosamine- 6 phosphate by the enzyme glutamine:fructose-6 phosphate amidotransferase (GFAT) [47]. When intracellular glucose levels rise, flux through this pathway increases. In

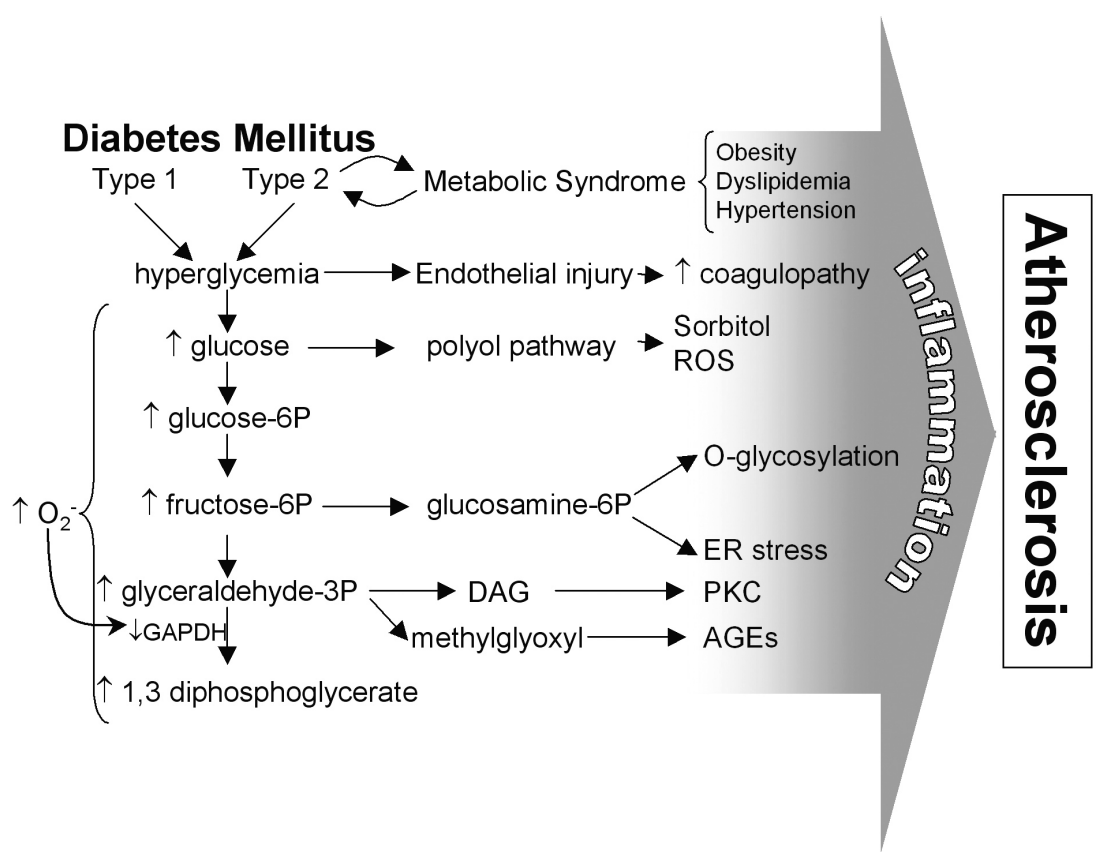

Figure 13.2. A summary of the potential links between diabetes mellitus, hyperglycemia, and accelerated atherosclerosis. 
addition, increased GFAT expression and activity have been reported in tissues from humans with diabetes [48]. Increased hexosamine pathway flux has been implicated in several diabetes-associated complications including; insulin resistance [47, 49], pancreatic $\beta$ cell death [50], as well as atherosclerosis [51]. While it is not entirely clear how hexosamine pathway byproducts promote cellular dysfunction most research has focused on the modification of proteins by $O$-linked glycosylation. The enzyme $O-N$-acetylglucosamine transferase (OGT) catalyses the addition of $N$-acetylglucosamine to serine and threonine residues of a variety of proteins. It is known that $O$-linked glycosylation can act in competition with phosphorylation of the same serine and threonine residues. It is well established that elevated glucosamine concentrations drive the $O$-linked glycosylation of proteins including transcription factors [52], nuclear pore proteins [53], as well as signaling factors [54] potentially altering their function, stability, and/or activity. Glucosamine has been shown to desensitize insulin-stimulated glucose uptake in both adipocytes [47] and skeletal muscle cells [55], probably by inhibiting the translocation of the glucose transporter, GLUT4, to the cell surface [56]. In addition, increased hexosamine pathway activity can promote the transcription of proinflammatory and prothrombotic factors including TGF- $\alpha$, TGF- $\beta$, and PAI-1 $[57,58]$. Therefore, the hyperglycemia-induced $O$-GlcNAc modification of proteins may change gene expression patterns and alter the function of specific factors that contribute to a proatherogenic, prothrombophilic vascular environment. More studies are required to test this theory and to precisely determine the factors and downstream pathways that may be involved in the acceleration of vascular disease.

\section{Endoplasmic Reticulum Stress Pathways}

Recently we have begun to investigate an additional intracellular effect of glucosamine that has not previously been examined in the context of diabetes and atherosclerosis - its ability to promote the accumulation of unfolded proteins in the endoplasmic reticulum (ER), thereby leading to ER dysfunction and cell injury [59-62]. In eukaryotic cells, the ER provides a contained environment for the synthesis and modification of membrane proteins and proteins destined to be secreted. These co- and posttranslational modifications, including disulfide bond formation and $\mathrm{N}$-linked glycosylation, play an important role in the subsequent folding and oligomeric assembly of proteins [63]. Misfolded polypeptides are retained in the ER and subsequently targeted for degradation [64, 65]. Agents or conditions that disrupt ER homeostasis by interfering with glycosylation, disulfide bond formation, $\mathrm{ER} \mathrm{Ca}^{2+}$ stores, and/or the general overloading of the ER with proteins will cause the accumulation of unfolded or misfolded proteins in the ER, a condition defined as ER stress (reviewed in [66, 67]).

In mammals, conditions of ER stress lead to the activation of the unfolded protein response (UPR) through activation of three distinct, integral ER 
membrane proteins designated PERK, Ire1, and ATF6 [67]. Together, these proteins signal (i) the general inhibition of protein expression, through the phosphorylation of the translation initiation factor eIF2 $\alpha$ [68], and (ii) the specific induction of ER-resident chaperone expression including GRP78, GRP94, PDI, and calreticulin, that function to assist in the folding of the accumulated polypeptides [69-71]. The ER stress response also induces the expression of the transcription factor, GADD153, which is known to play a role in ER stress-induced growth arrest and programmed cell death [72]. The ultimate fate of a cell is determined by the balance of protective (i.e., ER chaperone expression) and proapoptotic signals triggered by ER dysfunction. We have shown that glucosamine can induce ER stress in cells that are relevant to atherogenesis-including human macrophages, aortic SMCs, endothelial cells as well as hepatocytes (Ref. [62] and unpublished data).

In recent years additional cellular responses to ER stress have been identified (Fig. 13.3). Our lab and others have shown that ER stress can activate

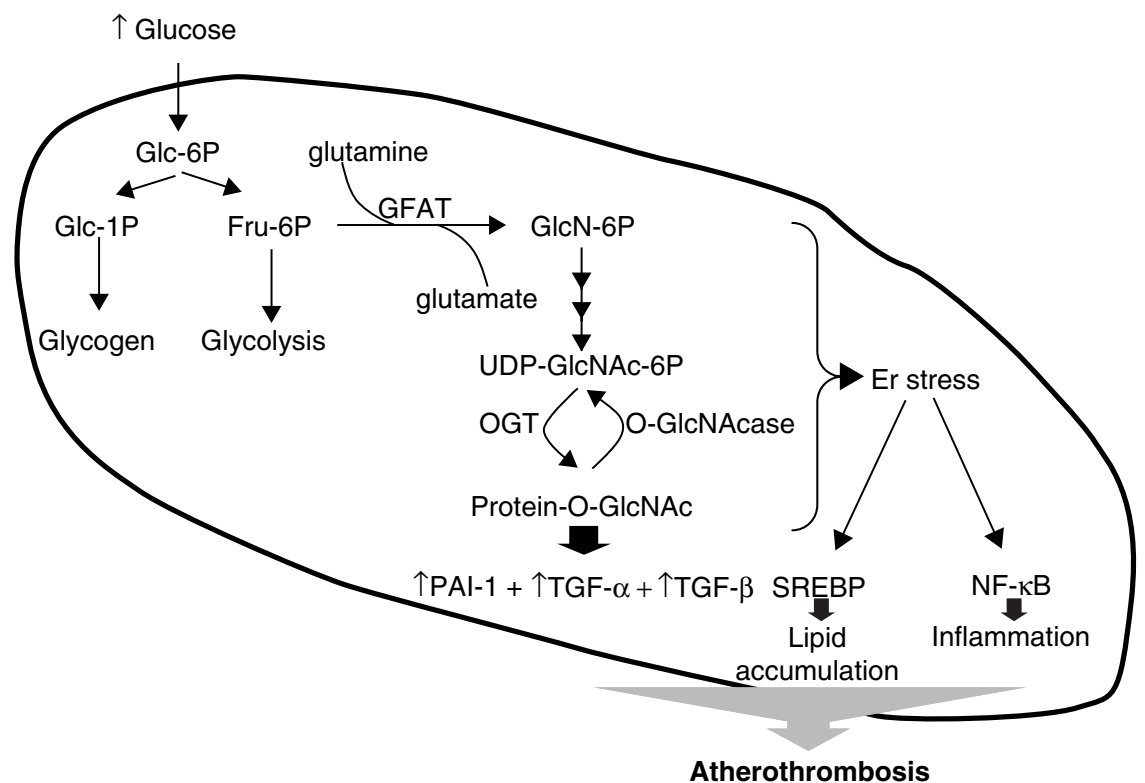

FIGURE 13.3. Links between the hexosamine pathway and atherothrombosis. The rate limiting enzyme of the hexosamine pathway, glutamine:fructose- 6 phosphate amidotransferase (GFAT) converts fructose-6 phosphate to glucosamine 6-phosphate (GlcN-6P). Glycosylation of serine and threonine residues of intracellular proteins is catalyzed by OGT, a reaction that is reversed by $O$-GlcNAcase. The $O$-linked glycosylation of transcription factors including SP-1 have been shown to increase expression levels of PAI-1, TGF- $\alpha$, and TGF- $\beta$. Glucosamine and/or downstream metabolites of glucosamine can also promote endoplasmic reticulum (ER) stress leading to lipid accumulation and activation of intracellular inflammatory pathways through the activation of the transcription factors SREBP and NF- $\mathrm{KB}$, respectively. 
and dysregulate the sterol regulatory element binding proteins (SREBPs), transcription factors that control lipid biosynthesis and uptake [62, 73, 74]. ER stress-inducing agents have been shown to promote the activation of $\mathrm{NF}-\kappa \mathrm{B}$, the transcription factor that is responsible for promoting the expression of genes involved in inflammatory processes [75]. Finally, ER stress has been shown to induce the activation of caspases and promote apoptosis of human aortic endothelial cells and hepatocytes $[62,76]$. Together, the dysregulation of lipid metabolism, activation of inflammatory pathways, and the induction of cell-specific apoptosis represent the hallmark features of atherosclerosis. In addition to glucosamine, other independent cardiovascular risk factors including homocysteine [73] and obesity [77] as well as the accumulation of intracellular free cholesterol [78] have been shown to induce ER stress. Thus ER stress pathway may be a common mechanism of general atherogenesis.

The potential role of ER stress-induced cellular dysfunction in the development and/or progression of human disease make this pathway a plausible therapeutic target. Studies are underway to develop and test potential antiatherogenic interventions that target ER stress pathways in models of diabetes mellitus.

\section{Protein Kinase C Activation}

The ubiquitous protein kinase $\mathrm{C}$ (PKC) family of signaling factors are known to play an important role in vascular function and in the pathogenesis of micro- and macrovascular disease. Specifically, glucose-induced PKC activation has been implicated in decreased endothelial vasodilation [79] and increased production of ROS [80] that could contribute to endothelial dysfunction. PKC inhibition blocks endothelial expression and activity of a number of adhesion molecules, including ICAM-1, P-, and E-selectins, under conditions of elevated glucose concentration [81]. AngII- and oxLDLinduced VSMC proliferation is dependent upon PKC activity [82, 83]. PKC may also be involved in foam cell formation through its involvement in the induction of receptors for oxidized LDL macrophages [84]. Most PKC isoforms can be activated by diacylglycerol (DAG), an intermediary of glucose and fat metabolism, and conditions of diabetes and high glucose concentration have been shown to increase membrane-associated PKC activity via the DAG activation pathway in cultured VSMCs and in animal models [85]. In addition, it has been proposed the PKC may also be activated by AGE-RAGE signaling pathways (see below). Selective inhibitors of PKC have shown promise in blocking nephropathy and retinopathy in animal models of diabetes [86]; however, there is no direct evidence that these inhibitors affect atherogenesis. The ubiquitous nature of expression, the large number of PKC isoforms and the lack of isoform-specific inhibitors are complicating factors in determining the potential role of this kinase in atherogenesis. 


\section{Advanced Glycation Endproducts}

AGEs are formed through a nonenzymatic process, known as the Maillard reaction, involving the reaction of the aldehyde groups of reducing sugars with the amino groups of proteins [87, 88] (Fig. 13.4). Because the reaction is nonspecific, requiring only a free amine, AGEs are a very heterogeneous group of compounds. The final step in the reaction, the conversion of Amidori products into cross-linked advanced glycation products, occurs very slowly in vivo, and therefore AGEs are predominantly composed of stable proteins with long half-lives such as collagen, laminin, and lens crystallins.

AGEs gradually accumulate during the natural aging process and have been implicated in characteristic changes associated with aging including the loss of collagen elasticity and flexibility, the formation of cataracts and $\beta$ amyloid plaques [89]. Formation of AGEs has been noted during the heating of food however, in healthy individuals, AGEs are poorly absorbed by the gut and rapidly cleared by the kidney [90]. Individuals with impaired renal function, a common complication of diabetes, are especially prone to the accumulation of dietary AGEs and therefore exogenous sources of AGEs may play a significant role in this population [91, 92].

In vivo, the Maillard reaction rate is directly proportional to the prevailing glucose concentration resulting in the enhanced levels of AGEs and AGE

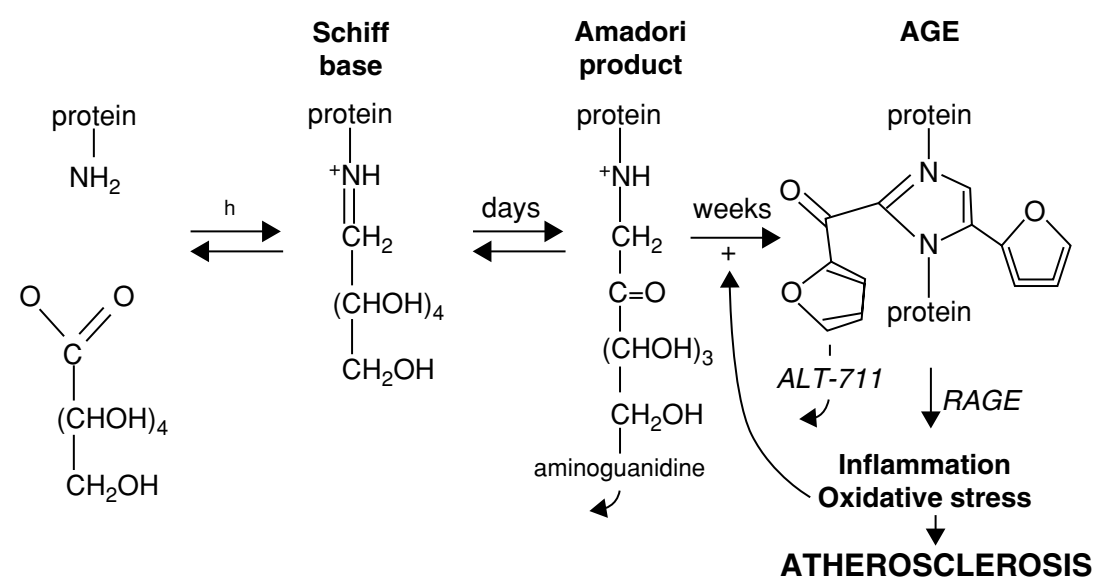

FIGURE 13.4. The formation of advanced glycation endproducts (AGE) by the Mallaird reaction. AGEs are produced by a multistep reaction involving the sequential formation of Schiff bases, Amidori products, and finally a heterogenous population of cross-linked advanced glycation endproducts. AGEs can interact with cellular receptors (RAGE) that activate intracellular inflammatory pathways and the production of ROS that may contribute to atherogenesis. Conditions of oxidative stress can also accelerate the formation of AGEs. The possible sites of post-Amidori-cross-link elimination by aminoguanidine and the cross-link breaker, ALT-711, are indicated. 
intermediates in individuals with diabetes mellitus. This is clearly demonstrated by the routine clinical use of the Amadori-intermediate, glycated hemoglobin (HbAlc), as a diagnostic marker of chronic hyperglycemia.

The association of AGEs with chronic hyperglycemia has attracted a great deal of interest into the possible role of AGEs in diabetic complications. There are several potential ways that AGE-modified proteins could be damaging; the formation of AGEs may alter protein function [93], disrupt extracellular matrix [94, 95], and/or lead to the modification of lipoprotein particles thereby increasing their atherogenicity. However it now appears that the predominant vascular effect of AGEs occurs through their interaction with RAGE (receptor for AGE) found on macrophages, endothelial, and SMCs [96-98]. The AGE-RAGE interaction triggers a signal transduction cascade that results in the production of intracellular reactive oxidative species that can initiate an inflammatory response $[99,100]$. The presence of ROS also feed back to accelerate the formation of AGEs.

There is a great deal of evidence supporting a role for AGEs in microvascular disease. AGEs accumulate in the kidney, retina, and peripheral nerve of diabetic rats [101]. Nephropathy can be induced in nondiabetic animals by the administration of AGEs [91, 92]. Neutralizing antibodies against RAGE also slow the progression of nephropathy in diabetic mice [102]. The administration of compounds that block AGE cross-linking (aminoguanidine and pyridoxamine) or interventions that break established cross-links (3-phenacyl-4,5-dimethylthiazolium chloride or ALT-711) have been shown to be protective against nephropathy and cardiovascular stiffness in diabetic models $[93,103]$.

There is a growing body of evidence supporting a role for AGEs in the development of atherosclerosis. AGEs have been localized to atherosclerotic plaques and RAGE is expressed by vascular endothelial cells, SMCs, and macrophages [104, 105]. Administration of both aminoguanidine and the AGE cross-link breaker, ALT-711, are associated with a significant decrease in plaque area and complexity in diabetic ApoE $-I-$ mice [106]. The strongest evidence in support of the AGE-RAGE pathway comes from experiments that focus upon interfering with receptor function. This has been accomplished using a soluble form of RAGE (sRAGE) that retains its ligand binding ability [107]. Daily intraperitoneal injections of sRAGE into STZ-induced diabetic mice showed dose-dependent attenuation of early lesion development in terms of lesion area at the aortic root and lesion complexity relative to controls. Importantly, plasma glucose and lipid levels were not affected by sRAGE treatment suggesting the effect was glycemia and lipid independent [107]. It has further been demonstrated that sRAGE can block the progression and even induce the regression of established lesions in diabetic mice [108]. In support of these findings, in vascular damage assays RAGE null mice show [109] decreased intimal/medial thickening. As of yet there have been no published reports to show the effects of the RAGE knockout genotype on plaque development in mouse models of diabetes-accelerated atherosclerosis. 
Interventions that interfere with AGE formation and action have shown some beneficial effects at the clinical level [110]. ALT-711 (under the commercial name, Alagebrium) has demonstrated safety and efficacy in a phase II clinical trial in the treatment of systolic hypertension and heart failure, conditions associated with vascular stiffening likely resulting from collagen cross-linking [111].

Some controversy still remains regarding the role of AGEs in atherosclerosis, in part due to the ability of other ligands, including cytokines of the S100/calgranulin family, to interact with and activate RAGE $[112,113]$. The role of AGE-RAGE is further complicated by the fact that virtually every large, well-controlled clinical trial has shown that antioxidant supplementation has no positive impact on cardiovascular risk in diabetic patients [114-117]. This paradox supports the possibility that other, AGE-independent, mechanisms and pathways may play an important role in the atherogenic process.

It is important to note that the above mechanisms are not mutually exclusive. Atherosclerosis is a complex disease that involves the interaction of several different cell types and many different molecular factors. Therefore, it is very possible that atherogenesis is regulated and affected by several independent and interdependent pathways that are altered under conditions of hyperglycemia. Furthermore, diabetes mellitus, especially T2D, is often associated with a cluster of conditions including hypertension, obesity, and dyslipidemia - each a CVD risk factor in its own right. Thus the interplay between this combination of risk factors in the context of a particular genetic background and modulated by a myriad of environmental influences will all contribute to the development and progression of the disease.

\section{Conclusions}

Because of the cardiovascular risks of diabetes and the increasing prevalence of T2D, it is essential that we further increase our knowledge of how and why diabetes mellitus and hyperglycemia promote CVD. Currently, and for the near future, the primary strategy for managing CVD in the diabetic population will be through the control of hyperglycemia and through the treatment of associated complications such as hypertension and dyslipidemia using established medications such as ACE inhibitors, statins, and fibrates.

The continued identification and investigation of existing and novel pathways linking hyperglycemia and diabetes mellitus to atherosclerosis is important to the development of new and effective antiatherosclerotic therapies that are tailored to individuals with diabetes. A great deal of research has been focused upon the role of hyperglycemia in the development and progression of atherosclerosis in cell culture and animal model systems. Several mechanisms have been identified that appear to link glucose to proatherogenic processes. The most promising of these; the polyol pathway, 
PKC activation, the hexosamine pathway, and the AGE-RAGE interaction show potential and are actively being evaluated as targets for putative antiatherogenic therapies. Thus far, however, all interventions targeting the effects of hyperglycemia, including direct glucose lowering, appear to show greater effect in the treatment of microvascular complications than in the control of macrovascular disease. This is likely due, at least in part, to the complexities of atherosclerosis and current limitations of the animal models available to researchers who study the development and progression of atherosclerosis. Additional studies are obviously required to further improve our understanding of this important disease.

Acknowledgments: G.H. Werstuck is supported by a New Investigator Award from the Heart and Stroke Foundation of Canada and research grants from the Canadian Institutes of Health Research (MOP-62910) and the Heart and Stroke Foundation of Ontario (NA5556).

\section{References}

1. King H, Aubert RE, Herman WH: Global burden of diabetes, 1995-2025: prevalence, numerical estimates, and projections. Diabetes Care 21: 1414-1431, 1998.

2. Zimmet P, Alberti KGMM, Shaw J: Global and societal implications of the diabetes epidemic. Nature 414: 782-788, 2001.

3. Kannel WB, McGee DL: Diabetes and cardiovascular disease. The Framingham study. JAMA 241: 2035-2038, 1979.

4. Haffner SM, Lehto S, Ronnemaa T, Pyorala K, Laakso M: Mortality from coronary heart disease in subjects with type 2 diabetes and in nondiabetic subjects with and without prior myocardial infarction. N Engl J Med 339: 229-234, 1998.

5. Resnick HE, Howard BV: Diabetes and cardiovascular disease. Annu Rev Med 53: 345-367, 2002.

6. Canadian Diabetes Association Clinical Practice Guidelines Experts Committee: Definition, classification and diagnosis of diabetes and other dysglycemic categories. Canadian J Diabetes 27: S7-S9, 2003.

7. Tisch R, McDevitt H: Insulin dependent diabetes mellitus. Cell 85: 291-297, 1906.

8. Mathis D, Vence L, Benoist C: $\beta$ cell death during progression to diabetes. Nature 414: 792-798, 1998.

9. Ginsberg HN: Insulin resistance and cardiovascular disease. J Clin Invest 106: 453-458, 2000.

10. Bell GI, Polonsky KS: Diabetes mellitus and genetically programmed defect in $\beta$-cell function. Nature 414: 788-791, 2001.

11. The Diabetes Control and Complications Trial/Epidemiology of Diabetes Interventions and Complications Research Group: Intensive diabetes therapy and carotid intima-medial thickness in type 1 diabetes mellitus. New Engl J Med 348: 2294-2303, 2003.

12. UK Prospective Diabetes Study (UKPDS) Group: Intensive blood-glucose control with sulphonylureas or insulin compared with conventional treatment and risk of complications in patients with type 2 diabetes (UKSPDS 33). Lancet 352: 837-853, 1998 . 
13. Haffner SM: The importance of hyperglycemia in the nonfasting state to the development of cardiovascular disease. Endocrine Rev 19: 583-592, 1998.

14. Standl E, Balletshofer B, Dahl B, Weichenhain B, Steigler H, Hormann A, Holl $\mathrm{R}$ : Predictors of 10-year macrovascular and overall mortality in patients with NIDDM: the Munich General Practitioner Project. Diabetologia 39: 1540-1545, 1996.

15. Lehto S, Ronnemaa T, Haffner SM, Pyorala K, Kallio V, Laakso M: Dyslipidemia and hyperglycemia predict coronary heart disease events in middle-aged patients with NIDDM. Diabetes 46: 1354-1359, 1997.

16. Santilli SM, Fiegel VD, Aldridge DE, Knighton DR: The effect of diabetes on the proliferation of aortic endothelial cells. Ann Vasc Surg 6: 503-510, 1992.

17. Huvers FC, De Leeuw PW, Houben AJ, De Haan CH, Hamulyak K, Schouten H, Wolffenbuttel BH, Schaper NC: Endothelium-dependent vasodilatation, plasma markers of endothelial function, and adrenergic vasoconstrictor responses in type 1 diabetes under near-normoglycemic conditions. Diabetes 48: 1300-1307, 1999.

18. Quagliaro L, Piconi L, Assaloni R, Martinelli L, Motz E, Ceriello A: Intermittent high glucose enhances apoptosis related to oxidative stress in human umbilical vein endothelial cells: the role of protein kinase $\mathrm{C}$ and NAD(P)H-oxidase activation. Diabetes 52: 2795-2804, 2003.

19. Nathan DM, Lachin J, Cleary P, Orchard T, Brillon DJ, Backlund JY, O'Leary DH, Genuth S; Diabetes Control and Complications Trial, Epidemiology of Diabetes Interventions and Complications Research Group: Intensive diabetes therapy and carotid intima-media thickness in type 1 diabetes mellitus. $\mathrm{N}$ Engl J Med 348: 2294-2303, 2003.

20. Lawes CM, Parag V, Bennett DA, Suh I, Lam TH, Whitlock G, Barzi F, Woodward M; Asia Pacific Cohort Studies Collaboration: Blood glucose and risk of cardiovascular disease in the Asia Pacific region. Diabetes Care 27: 2836-2842, 2004.

21. Grundy SM, Brewer HB Jr, Cleeman JI, Smith SC Jr, Lenfant C; American Heart Association; National Heart, Lung, and Blood Institute: Definition of metabolic syndrome: Report of the National Heart, Lung, and Blood Institute/American Heart Association conference on scientific issues related to definition. Circulation 109: 433-438, 2004.

22. World Health Organization: Obesity: preventing and managing the global epidemic. (WHO Technical Report Series, No. 894), 2003.

23. Grundy SM: Metabolic complications of obesity. Endocrine 13: 155-165, 2000.

24. Kunjathoor VV, Wilson D, LeBoeuf RC: Increased atherosclerosis in streptozotocin-induced diabetic mice. J Clin Invest 97: 1767-1773, 1996.

25. Park L, Raman KG, Lee KJ, Lu Y, Ferran LJ Jr, Chow WS, Stern D, Schmidt AM: Suppression of accelerated diabetic atherosclerosis by the soluble receptor for advanced glycation endproducts. Nat Med 4: 1025-1031, 1998.

26. Fazio S, Linton MF: Mouse models of hyperlipidemia and atherosclerosis. Front Biosci 6: D515-D525, 2001.

27. Rees DA, Alcolado JC: Animal models of diabetes mellitus. Diabet Med 22: 359-370, 2005.

28. Breslow JL: Mouse models of atherosclerosis. Science 272: 685-688, 1996.

29. Szkudelski T: The mechanism of alloxan and streptozotocin action in B cells of the rat pancreas. Physiol Res 50: 537-546, 2001. 
30. Winterbourn CC, Munday R: Glutathione-mediated redox cycling of alloxan. Mechanisms of superoxide dismutase inhibition and of metal-catalyzed $\mathrm{OH}$ formation. Biochem Pharmacol 38: 271-277, 1989.

31. Schnedl WJ, Ferber S, Johnson JH, Newgard CB: STZ transport and cytotoxicity. Specific enhancement in GLUT2-expressing cells. Diabetes 43: 1326-1333, 1994.

32. Renard CB, Kramer F, Johansson F, Lamharzi N, Tannock LR, Herrath MG, Chait A, Bornfeldt KE: Diabetes and diabetes-associated lipid abnormalities have distinct effects on initiation and progression of atherosclerotic lesions. J Clin Invest 114: 659-668, 2004.

33. Reaven P, Merat S, Casandra F, Sutphin M, Palinski W: Effect of streptozotocininduced hyperglycemia on lipid profiles, formation of advanced glycation endproducts in lesions, and extent of atherosclerosis in LDL receptor-deficient mice. Arterioscler Thromb Vasc Biol 17: 2250-2256, 1997.

34. Kako Y, Huang L-S, Yang J, Katopodis T, Ramakrishnan R, Goldberg IJ: Streptozotocin-induced diabetes in human apolipoprotein B transgenic mice: effects on lipoproteins and atherosclerosis. J Lipid Res 40: 2185-2194, 1999.

35. Goldberg IJ, Isaacs A, Sehayek E, Breslow JL, Huang L-S: Effects of streptozotocin-induced diabetes in apolipoprotein AI deficient mice. Atherosclerosis 172: 47-53, 2004.

36. Hasty AH, Shimano H, Osuga J, Namatame I, Takahashi A, Yahagi N, Perrey S, Iizuka Y, Tamura Y, Amemiya-Kudo M, Yoshikawa T, Okazaki H, Ohashi K, Harada K, Matsuzaka T, Sone H, Gotoda T, Nagai R, Ishibashi S, Yamada N: Severe hypercholesterolemia, hypertriglyceridemia, and atherosclerosis in mice lacking both leptin and the low-density lipoprotein receptor. J Biol Chem 276: 37402-37408, 2001.

37. Ross R: Atherosclerosis - an inflammatory disease. New Engl J Med 340: 115-126, 1999.

38. Lusis AJ: Atherosclerosis. Nature 407: 233-241, 2000.

39. Drielsma RF, Burnett JR, Gray-Weale AC, Byrne K, Lusby RJ: Carotid artery disease: the influence of diabetes mellitus. J Cardiovasc Surg (Torino) 29: 692-696, 1988.

40. Silva JA, Escobar A, Collins TJ, Ramee SR, White CJ: Unstable angina. A comparison of angioscopic findings between diabetic and nondiabetic patients. Circulation 92: 1731-1736, 1995.

41. Srivastava SK, Ansari NH, Hair GA, Jaspan J, Rao MB, Das B: Hyperglycemiainduced activation of human erythrocyte aldose reductase and alterations in kinetic properties. Biochim Biophys Acta 870: 302-311, 1986.

42. Chung SS, Ho EC, Lam KS, Chung SK: Contribution of polyol pathway to diabetes-induced oxidative stress. J Am Soc Nephrol 14: S233-S236, 2003.

43. Greene DA, Arezzo JC, Brown MB, the Zenarestat Study Group: Effect of aldose reductase inhibition on nerve conduction and morphometry in diabetic neuropathy. Neurology 53: 580-591, 1999.

44. Sorbinil Retinopathy Trial Research Group: The Sorbinil Retinopathy Trial: Neuropathy results. Neurology 43: 1141-1149, 1993.

45. Engerman RL, Kern TS, Larson ME: Nerve conduction and aldose reductase inhibition during 5 years of diabetes or galactosaemia in dogs. Diabetologia 37: 141-144, 1994. 
46. Brown MJ, Bird SJ, Watling S, Kaleta H, Hayes L, Eckert S, Foyt HL; Zenarest study: Natural progression of diabetic peripheral neuropathy in the Zenarestat study population. Diabetes Care 27: 1153-1159, 2004.

47. Marshall S, Bacote V, Traxinger RR: Discovery of a metabolic pathway mediating glucose-induced desensitization of the glucose transport system. J Biol Chem 266: 4706-4712, 1991.

48. Nerlich AG, Sauer U, Kolm-Litty V, Wagner E, Koch M, Schleicher ED: Expression of glutamine:fructose-6-phosphate amidotransferase in human tissues: evidence for high variability and distinct regulation in diabetes. Diabetes 47: 170-178, 1998.

49. Herbert LF, Daniels MC, Zhou J, Crook ED, Turner RL, Simmons ST, Neidigh JL, Zhu JS, Baron AD, McClain DA: Overexpression of glutamine: fructose6-phosphate amidotransferase in transgenic mice leads to insulin resistance. J Clin Invest 98: 930-936, 1996.

50. Lui K, Paterson AJ, Chin E, Kudlow JE: Glucose stimulates protein modification by O-linked GlcNAc in pancreatic beta cells: linkage of O-linked GlcNAc to beta cell death. Proc Natl Acad Sci USA 14: 2820-2825, 2000.

51. Stender S, Astrup P: Glucosamine and experimental atherosclerosis. Increased wet weight and changed composition of cholesterol fatty acids in aorta of rabbits fed a cholesterol-enriched diet with added glucosamine. Atherosclerosis 26: 205-213, 1977.

52. Han I, Kudlow JE: Reduced O glycosylation of SP1 is associated with increased proteasome susceptibility. Mol Cell Biol 17: 2550-2558, 1997.

53. Han I, Oh E, Kudlow JE: Responsiveness of the state of O-linked $N$-acetylglucosamine modification of nuclear pore protein p62 to the extracellular glucose concentration. Biochem J 350: 109-114, 2000.

54. Du XL, Edelstein D, Dimmeler S, Ju Q, Sui C, Brownlee M: Hyperglycemia inhibits nitric oxide synthase activity by posttranslational modification at the Akt site. J Clin Invest 108: 1341-1348, 2001.

55. Hawkins M, Angelov I, Liu R, Barzilai N, Rossetti L: The tissue concentration of UDP- $N$-acetylglucosamine modulates the stimulatory effect of insulin on skeletal muscle glucose uptake. J Biol Chem 272: 4889-4895, 1997.

56. Ross SA, Chen X, Hope HR, Sun S, McMahon EG, Broschat K, Gulve EA: Development and comparison of two 3T3-L1 adipocyte models of insulin resistance: increased glucose flux vs glucosamine treatment. Biochem Biophys Res Commun 273: 1033-1041, 2000.

57. James LR, Fantus IG, Goldberg H, Ly H, Scholey JW: Overexpression of GFAT activates PAI-1 promoter in mesangial cells. Am J Physiol Renal Physiol 279: F718-F727, 2000.

58. Du X-L, Edelstein D, Rossetti L, Fantus IG, Goldberg H, Ziyadeh F, Wu J, Brownlee M: Hyperglycemia-induced mitochondrial superoxide overproduction activates the hexosamine pathway and induces plasminogen activator inhibitor-1 expression by increasing Sp1 glycosylation. Proc Natl Acad Sci USA 97: 12222-12226, 2000.

59. Morin MJ, Porter CW, McKernan P, Bernacki RJ: The biochemical and ultrastructural effects of tunicamycin and D-glucosamine in L1210 leukemic cells. J Cell Physiol 114: 162-172, 1983.

60. Lin H, Masso-Welsh P, Di Y, Cai J, Shen J, Subjeck JR: The 170-kDa glucoseregulated stress protein is an endoplasmic reticulum protein that binds immunoglobulin. Mol Biol Cell 4: 1109-1119, 1993. 
61. Miskovic D, Salter-Cid L, Ohan N, Flajnik M, Heikkila JJ: Isolation and characterization of a cDNA encoding a Xenopus immunoglobulin binding protein, BiP (GRP78). Comp Biochem Physiol 116: 227-234, 1997.

62. Kim AJ, Shi YY, Austin RC, Werstuck GH: Valproate protects cells from endoplasmic reticulum stress-induced lipid accumulation and apoptosis by inhibiting glycogen synthase kinase 3. J Cell Sci 118: 89-99, 2005.

63. Helenius A: How-linked oligosaccharides effect protein folding in the endoplasmic reticulum. Mol Biol Cell 5: 253-265, 1994.

64. Travers KJ, Patil CK, Wodicka L, Lockhart DJ, Weissman JS, Walter P: Functional and genomic analyses reveal an essential coordination between the unfolded protein response and ER-associated degradation. Cell 101: 249-258, 2000.

65. Friedlander R, Jarosch E, Urban J, Volkwein C, Sommer T: A regulatory link between ER-associated protein degradation and the unfolded-protein response. Nat Cell Biol 2: 379-384, 2000.

66. Pahl HL: Signal transduction from the endoplasmic reticulum to the cell nucleus. Physiol Rev 79: 683-701, 1999.

67. Kaufman RJ: Stress signalling from the lumen of the endoplasmic reticulum: coordination of gene transcriptional and translational controls. Genes Dev 13: 1211-1233, 1999.

68. Harding HP, Zhang Y, Ron D: Protein translation and folding are coupled by an endoplasmic-reticulum-resident kinase. Nature 397: 271-274, 1999.

69. Cox JS, Shamu CE, Walter P: Translational induction of genes encoding endoplasmic reticulum resident proteins requires a transmembrane protein kinase. Cell 73: 1197-1206, 1993.

70. Wang X-Z, Harding HP, Zhang Y, Jolicoeur EM, Kuroda M, Ron D: Cloning of mammalian Ire1 reveals diversity in the ER stress response. EMBO J 17: 5708-5717, 1998.

71. Yoshida H, Haze K, Yanagi H, Yura T, Mori K: Identification of the cis-acting endoplasmic reticulum stress response element responsible for the transcriptional induction of mammalian glucose-regulated proteins. J Biol Chem 273: 33741-33749, 1998.

72. Zinszner H, Kuroda M, Wang X-Z, Batchvarova N, Lightfoot RT, Remotti H, Stevens JL, Ron D: CHOP is implicated in programmed cell death in response to impaired function of the endoplasmic reticulum. Genes Dev 12: 982-995, 1998.

73. Werstuck GH, Lentz SR, Dayal S, Shi Y, Hossain GS, Sood SK, Krisans SK, Austin RC: Homocysteine causes dysregulation of the cholesterol and fatty acid biosynthesis pathways. J Clin Invest 107: 1263-1273, 2001.

74. Lee JN, Ye J: Proteolytic activation of SREBP induced by cellular stress through the depletion of Insig-1. J Biol Chem 279: 45257-45265, 2004.

75. Jiang H-Y, Wek SA, McGrath BC, Scheuner D, Kaufman RJ, Cavener DR, Wek RC: Phosphorylation of the alpha subunit of eukaryotic initiation factor 2 is required for activation of NF-kappaB in response to diverse cellular stresses. Mol Cell Biol 23: 5651-5663, 2003.

76. Hossain GS, van Thienen JV, Werstuck GH, Zhou J, Sood SK, Dickhout JG, de Koning AB, Tang D, Wu D, Falk E, Poddar R, Jacobsen DW Zhang K, Kaufman RJ, Austin RC: TDAG51 is induced by homocysteine, promotes detachment-mediated programmed cell death and contributes to the development of atherosclerosis in hyperhomocysteinemia. J Biol Chem 278: 30317-30327, 2003. 
77. Özcan U, Cao Q, Yilmaz E, Lee A-H, Iwakoshi NN, Özdelen E, Tuncman G, Görgun C, Glimcher LH, Hotamisligil GS: Endoplasmic reticulum stress links obesity, insulin action, and type 2 diabetes. Science 306: 457-461, 2004.

78. Li Y, Schwabe RF, Devries-Seimon T, Yao PM, Gerbod-Giannone MC, Tall AR, Davis RJ, Flavell R, Brenner DA, Tabas I: Free cholesterol-loaded macrophages are an abundant source of TNF-alpha and IL-6. Model of NF-kappa B- and MAP kinase-dependent inflammation in advanced atherosclerosis. J Biol Chem 280: 21763-21772, 2005.

79. Tesfamariam B, Brown ML, Cohen RA: Elevated glucose impairs endotheliumdependent relaxation by activating protein kinase C. J Clin Invest 87: 1643-1648, 1991.

80. Inoguchi T, Li P, Umeda F, Yu HY, Kakimoto M, Imamura M, Aoki T, Etoh T, Hashimoto T, Naruse M, Sano H, Utsumi H, Nawata H: High glucose level and free fatty acid stimulate reactive oxygen species production through protein kinase $\mathrm{C}$ - dependent activation of NAD $(\mathrm{P}) \mathrm{H}$ oxidase in cultured vascular cells. Diabetes 49: 1939-1945, 2000.

81. Omi H, Okayama N, Shimizu M, Okouchi M, Ito S, Fukutomi T, Itoh M: Participation of high glucose concentrations in neutrophil adhesion and surface expression of adhesion molecules on cultured human endothelial cells: effect of antidiabetic medicines. J Diabetes Complications 16: 201-208, 2002.

82. Yang CM, Chien CS, Hsiao LD, Pan SL, Wang CC, Chiu CT, Lin CC: Mitogenic effect of oxidized low-density lipoprotein on vascular smooth muscle cells mediated by activation of Ras/Raf/MEK/MAPK pathway. Br J Pharmacol 132: 1531-1541, 2001.

83. Greene EL, Lu G, Zhang D, Egan BM: Signaling events mediating the additive effects of oleic acid and angiotensin II on vascular smooth muscle cell migration. Hypertension 37: 308-312, 2001.

84. Li L, Sawamura T, Renier G: Glucose enhances human macrophage LOX-1 expression: role for LOX-1 in glucose-induced macrophage foam cell formation. Circ Res 94: 892-901, 2004.

85. Inoguchi T, Xia P, Kunisaki M, Higashi S, Feener EP, King GL: Insulin's effect on protein kinase $\mathrm{C}$ and diacylglycerol induced by diabetes and glucose in vascular tissues. Am J Physiol 267: E369-E379, 1994.

86. Ishii H, Jirousek MR, Koya D, Takagi C, Xia P, Clermont A, Bursell SE, Kern TS, Ballas LM, Heath WF, Stramm LE, Feener EP, King GL: Amelioration of vascular dysfunctions in diabetic rats by an oral PKC beta inhibitor. Science 272: 728-731, 1996.

87. Wells-Knecht KJ, Zyzak DV, Litchfield JE, Thorpe SR, Baynes JW: Mechanism of autoxidative glycosylation: identification of glyoxal and arabinose as intermediates in the autoxidative modification of proteins by glucose. Biochemistry 34: 3702-3709, 1995.

88. Degenhardt TP, Thorpe SR, Baynes JW: Chemical modification of proteins by methylglyoxal. Cell Mol Biol 44: 1139-1145, 1998.

89. Ulrich P, Cerami A: Protein glycation, diabetes, and aging. Recent Prog Horm Res 56: 1-21, 2001.

90. Sgarbieri VC, Amaya J, Tanaka M, Chichester CO: Nutritional consequences of the Maillard reaction. Amino acid availability from fructose-leucine and fructose-tryptophan in the rat. J Nutr 103: 657-663, 1973. 
91. Makita Z, Radoff S, Rayfield EJ, Yang Z, Skolnik E, Delaney V, Friedman EA, Cerami A, Vlassara $\mathrm{H}$ : Advanced glycosylation end products in patients with diabetic nephropathy. N Engl J Med 325: 836-842, 1991.

92. Koschinsky T, He C-J, Mitsuhashi T, Bucala R, Liu C, Buenting C, Heitmann $\mathrm{K}$, Vlassara H: Orally absorbed reactive glycation products (glycotoxins): an environmental risk factor in diabetic nephropathy Proc Natl Acad Sci USA 94: 6474-6479, 1997.

93. Liu J, Masurekar MR, Vatner DE, Jyothirmayi GN, Regan TJ, Vatner SF, Meggs LG, Malhotra A: Glycation end-product cross-link breaker reduces collagen and improves cardiac function in aging diabetic heart. Am J Physiol Heart Circ Physiol 285:H2587-H2591, 2003.

94. Tanaka S, Avigad G, Brodsky B, Eikenberry EF: Glycation induces expansion of the molecular packing of collagen. J Mol Biol 203: 495-505, 1988.

95. Haitoglou CS, Tsilibary EC, Brownlee M, Charonis AS: Altered cellular interactions between endothelial cells and nonenzymatically glucosylated lamin/type IV collagen. J Biol Chem 267: 12404-12407, 1992.

96. Neeper M, Schmidt AM, Brett J, Yan SD, Wang F, Pan YC, Elliston K, Stern D, Shaw A: Cloning and expression of a cell surface receptor for advanced glycation end products of proteins. J Biol Chem 267: 14998-15004, 1992.

97. Li YM, Mitsuhashi T, Wojciechowicz D, Shimizu N, Li J, Stitt A, He C, Banerjee D, Vlassara H: Molecular identity and cellular distribution of advanced glycation endproduct receptors: relationship of p60 to OST-48 and p90 to $80 \mathrm{~K}-\mathrm{H}$ membrane proteins. Proc Natl Acad Sci USA 93: 11047-11052, 1997.

98. Smedsrod B, Melkko J, Araki N, Sano H, Horiuchi S: Advanced glycation end products are eliminated by scavenger-receptor-mediated endocytosis in hepatic sinusoidal Kupffer and endothelial cells. Biochem J 322: 567-573, 1997.

99. Hofmann MA, Lalla E, Lu Y, Gleason MR, Wolf BM, Tanji N, Ferran LJ Jr, Kohl B, Rao V, Kisiel W, Stern DM, Schmidt AM: Hyperhomocysteinemia enhances vascular inflammation and accelerates atherosclerosis in a murine model. J Clin Invest 107: 675-683, 2001.

100. Lander HM, Taurus JM, Ogiste JS, Hori O, Moss RA, Schmidt AM: Activation of the receptor for advanced glycation end products triggers a p21(ras)-dependent mitogen-activated protein kinase pathway regulated by oxidative stress. J Biol Chem 272: 17810-17814, 1997.

101. Karachalias N, Babaei-Jadidi R, Ahmed N, Thornalley PJ: Accumulation of fructosyl-lysine and advanced glycation end products in the kidney, retina and peripheral nerve of streptozotocin-induced diabetic rats. Biochem Soc Trans 31: 1423-1425, 2003.

102. Flyvbjerg A, Denner L, Schrijvers BF, Tilton RG, Mogensen TH, Paludan SR, Rasch R: Long-term renal effects of a neutralizing RAGE antibody in obese type 2 diabetic mice. Diabetes 53: 166-172, 2004.

103. Forbes JM, Thallas V, Thomas MC, Founds HW, Burns WC, Jerums G, Cooper ME: The breakdown of pre-existing advanced glycation end products is associated with reduced renal fibrosis in experimental diabetes. FASEB J 17: 1762-1764, 2003.

104. Meng J, Sakata N, Takebayashi S, Asano T, Futata T, Araki N, Horiuchi S: Advanced glycation end products of the Maillard reaction in aortic pepsininsoluble and pepsin-soluble collagen from diabetic rats. Diabetes 45: 1037-1043, 1996. 
105. Brett J, Schmidt AM, Yan SD, Zou YS, Weidman E, Pinsky D, Nowygrod R, Neeper M, Przysiecki C, Shaw A: Survey of the distribution of a newly characterized receptor for advanced glycation end products in tissues. Am J Pathol 143: 1699-1712, 1993.

106. Forbes JM, Yee LT, Thallas V, Lassila M, Candido R, Jandeleit-Dahm KA, Thomas MC, Burns WC, Deemer EK, Thorpe SM, Cooper ME, Allen TJ: Advanced glycation end product interventions reduce diabetes-accelerated atherosclerosis. Diabetes 53: 1813-1823, 2004.

107. Park L, Raman KG, Lee KJ, Lu Y, Ferran LJ, Chow WS, Stern D, Schmidt AM: Suppression of accelerated diabetic atherosclerosis by the soluble receptor for advanced glycation endproducts. Nat Med 4: 1025-1031, 1998.

108. Bucciarelli LG, Wendt T, Qu W, Lu Y, Lalla E, Rong LL, Goova MT, Moser B, Kislinger T, Lee DC, Kashyap Y, Stern DM, Schmidt AM: RAGE blockade stabilizes established atherosclerosis in diabetic apolipoprotein E-null mice. Circulation 106: 2827-2835, 2002.

109. Sakaguchi T, Yan SF, Yan SD, Belov D, Rong LL, Sousa M, Andrassy M, Marso SP, Duda S, Arnold B, Liliensiek B, Nawroth PP, Stern DM, Schmidt AM, Naka Y: Central role of RAGE-dependent neointimal expansion in arterial restenosis. J Clin Invest 111: 959-972, 2003.

110. Williams ME: Clinical studies of advanced glycation end product inhibitors and diabetic kidney disease. Curr Diab Rep 4: 441-446, 2004.

111. Little WC, Zile MR, Kitzman DW, Hundley WG, O'Brien TX, Degroof RC: The effect of alagebrium chloride (ALT-711), a novel glucose cross-link breaker, in the treatment of elderly patients with diastolic heart failure. J Card Fail 11: 191-195, 2005.

112. Valencia JV, Mone M, Koehne C, Rediske J, Hughes TE: Binding of receptor for advanced glycation end products (RAGE) ligands is not sufficient to induce inflammatory signals: lack of activity of endotoxin-free albumin-derived advanced glycation end products. Diabetologia 47: 844-852, 2004.

113. Valencia JV, Zhang MM, Weetall M, Buxton FP, Hughes TE: Divergent pathways of gene expression are activated by the RAGE ligands S100b and AGEBSA. Diabetes 53: 743-751, 2004.

114. Heart Outcomes Prevention Evaluation Study Investigators: Effects of ramipril on cardiovascular and microvascular outcomes in people with diabetes mellitus: results of the HOPE study and MICRO-HOPE substudy. Lancet 355: 253-259, 2000.

115. Lonn EM, Yusuf S, Dzavik V, Doris CI, Yi Q, Smith S, Moore-Cox A, Bosch J, Riley WA, Teo KK, for the SECURE Investigators: Effects of Ramipril and vitamin $\mathrm{E}$ on atherosclerosis. The study to evaluate cartotid ultrasound changes in patients treated with ramipril and vitamin E (SECURE). Circulation 103: 919-925, 2001.

116. McQuillan BM, Hung J, Beilby JP, Nidorf M, Thompson PL: Antioxidant vitamins and the risk of carotid atherosclerosis. The Perth carotid ultrasound disease assessment study (CUDAS). J Am Coll Cardiol 38: 1788-1784, 2001.

117. Lonn E, Bosch J, Yusuf S, Sheridan P, Pogue J, Arnold JM, Ross C, Arnold A, Sleight P, Probstfield J, Dagenais GR, HOPE and HOPE-TOO Trial Investigators: Effects of long-term vitamin E supplementation on cardiovascular events and cancer: a randomized controlled trial. JAMA 293: 1338-1347, 2005. 